\title{
Um Economista no Labirinto: Um Obituário de Antônio Barros de Castro
}

\author{
Luiz Carlos Delorme Prado ${ }^{1}$ \\ Eduardo F. Bastian ${ }^{2}$ \\ ${ }^{1}$ Instituto de Economia da Universidade Federal do Rio de Janeiro (UFRJ) e \\ diretor-presidente do Centro Internacional Celso Furtado de Políticas para 0 \\ Desenvolvimento. Rio de Janeiro, RJ, Brasil (e-mail: lcdprado@gmail.com). \\ ${ }^{2}$ Instituto de Economia da Universidade Federal do Rio de Janeiro (IE/UFRJ). Rio de Janeiro, \\ RJ, Brasil (e-mail: eduardobastian@ie.ufrj.br).
}

E m 1962, Celso Furtado publicou um pequeno livro que reunia um conjunto de ensaios escritos para a juventude universitária brasileira da época (Furtado, [1962] 2009). Furtado observava que tinha se generalizado a consciência de que o país caminhava para transformações de grande alcance. E ainda, que havia uma grande preocupação dos estudantes em entender o que estava ocorrendo e como participar ativamente dessas transformações. Para Furtado, o desenvolvimento trouxe a capacidade de mudar a economia brasileira e a vida dos brasileiros a partir de forças internas ao país: o Brasil não seria mais um observador passivo da arena internacional, refém da economia mundial para construir seu futuro. Para Furtado, a industrialização brasileira no pós-guerra tinha criado condições para aumentar a autonomia de decisão, ou seja, o país teria condições de escolher suas trajetórias. Essa interpretação tinha um corolário: ela impunha a essa geração criada nessa mentalidade a consciência que eram senhores do próprio destino e, portanto, tinham a imensa responsabilidade de trabalhar pela continuidade do desenvolvimento brasileiro. Isto fazia aqueles jovens se sentirem responsáveis e intranquilos.

Mas se o futuro podia ser forjado pela ação de forças internas ao país, os caminhos a serem percorridos tinham de ser descobertos. Havia muitas trajetórias possíveis, o caminho do desenvolvimento brasileiro teria que ser percorrido em um labirinto de alternativas.

DADOS - Revista de Ciências Sociais, Rio de Janeiro, vol. 54, n-3, 2011, pp. 243 a 258. 
Naquela mesma década discutiam-se as reformas necessárias para a continuidade da industrialização ${ }^{1}$. No início dos anos 1960, em muitos países latino-americanos, a fase mais fácil da industrialização - baseada na substituição de importações de bens de consumo não duráveis tinha se esgotado. O Brasil, beneficiado pelo tamanho de seu mercado interno, tinha conseguido grandes avanços, com a criação de indústria de bens de consumo duráveis. Todavia, mesmo assim o país enfrentava então grandes dificuldades econômicas e o aprofundamento da industrialização estava ameaçado.

Foi nesse contexto que, em novembro de 1962, o jovem economista Antônio Barros de Castro retornou ao Brasil. Financiado por uma bolsa da Rockefeller Foundation, recém-graduado em economia pela Universidade Federal do Rio de Janeiro (UFRJ), Castro passou dois anos na Europa, estudando em Londres, na London School of Economics (LSE), e em Paris, onde acompanharia cursos de estatística com Edmond Malinvaud no Centre d'Études de Programmes Économiques. Em seu retorno, por intermédio de seus ex-colegas de faculdade, Carlos Lessa e Maria da Conceição Tavares, conheceu Aníbal Pinto e foi trabalhar no escritório da Comissão Econômica para a América Latina e o Caribe (CEPAL)-Banco Nacional de Desenvolvimento Econômico e Social (BNDES).

Castro lembrou, em uma entrevista, que ficou impressionado com a politização do país, muito diferente de quando tinha saído, lembrando que era a época do livro de Furtado (A Pré-Revolução Brasileira, de 1962), e ainda, do nome feliz de sua tradução para o francês: Le Brésil a $l^{\prime}$ Heure du Choix $(1964)^{2}$. No ano seguinte escreveu, com Carlos Lessa, um manual de introdução à economia para os cursos da CEPAL, que foi um dos livros de economia mais vendidos da história do Brasil, transformando esses dois jovens economistas em nomes conhecidos e dando origem a uma notável carreira acadêmica e profissional (ver Castro e Lessa, 1967). Desde essa época, ao longo de mais de quatro décadas, esse autor participaria ativamente da vida acadêmica do país, contribuindo para a interpretação da economia brasileira e discutindo opções para uma estratégia de desenvolvimento.

Castro fez parte de uma geração de professores que influenciou não apenas o debate acadêmico, mas também as interpretações da sociedade brasileira sobre seus problemas e alternativas. A expressão Intelectual Público foi atribuída a pessoas que debatiam ideias, não apenas no 
meio acadêmico, mas por intermédio da imprensa e de outros meios, influenciando a opinião pública ${ }^{3}$. Sartre, um dos autores que Castro apreciava, afirmava que os intelectuais deveriam ser a consciência moral de seu tempo ${ }^{4}$. Castro, junto aos seus colegas na graduação da UFRJ, Maria da Conceição Tavares e Carlos Lessa, foram, durante muitos anos, os mais atuantes representantes da tradição estruturalista da CEPAL no Brasil. Nesse sentido, esse grupo podia ser legitimamente chamado de intelectuais públicos. Eles eram convidados para um número imenso de palestras, conferências, aberturas de Congressos e eventos públicos. Suas ideias e opiniões eram ouvidas e debatidas não apenas por estudantes e acadêmicos, mas por um amplo público culto interessado nas questões que discutiam.

No entanto, se a palavra scholar ${ }^{5}$ significa aquele que tem por profissão a atividade de pesquisar, pensar, escrever e ensinar - entre eles, Castro é o que melhor poderia ser considerado como tal. Castro, por temperamento e formação, foi sempre cuidadoso com as palavras e detalhista nas ideias. Participou de inúmeras controvérsias, mas elas foram (quase) sempre debates intelectuais. Discordava com elegância e defendia suas ideias com serenidade.

Entre os debates de que participou, vale a pena lembrar alguns. Castro defendeu, no livro Sete Ensaios sobre a Economia Brasileira, a tese de que a agricultura brasileira não constituiu um freio à industrialização (ver Castro, 1972 [1969]). Para ele, embora a agricultura não tenha cumprido o papel clássico que esse setor exerceu nos países desenvolvidos, ela não foi funcional na substituição de importações. No entanto, ao colocar nas cidades seus excedentes de população de despossuídos e sem instrução, a estrutura agrária contribuiu para reproduzir nos centros urbanos a desigualdade que havia no campo.

É interessante notar que esse autor foi um dos primeiros que afirmou que a distribuição de renda brasileira - embora iníqua - não levaria à estagnação da economia brasileira, como defendiam Tavares e o próprio Furtado ao final da década de 1960. Nesse sentido, antecipou uma interpretação que depois seria retomada pelo próprio Furtado em $O$ Modelo Brasileiro, e por Tavares e Serra, em Além da Estagnação, que a concentração de renda poderia favorecer o crescimento da demanda de bens de consumo para uma parcela da população beneficiária desse processo (ver Furtado, 1972) ${ }^{6}$. 
O "Ensaio 2", do livro Sete Ensaios..., é uma das mais instigantes interpretações sobre a relação de agricultura e indústria escrita no Brasil. ${ }^{7} \mathrm{O}$ trabalho é contemporâneo do artigo de Waltkins que formaliza a chamada Staple Theory, que é a principal contribuição dos historiadores econômicos canadenses para a discussão do desenvolvimento econômico em condições de oferta elástica de recursos naturais (ver Watkins, 1963) ${ }^{8}$. Castro não faz referência aos historiadores econômicos canadenses e provavelmente não tinha conhecimento desses trabalhos, mas as duas abordagens discutem as implicações da estrutura agrária em países originalmente periféricos, mostrando que uma grande oferta de recursos naturais pode ser funcional ao desenvolvimento econômico.

Castro argumentou que a agricultura brasileira contribuiu com a industrialização por meio da geração e permanente ampliação de excedente de alimentos e matérias-primas, da liberação da mão de obra e da transferência de capitais. O autor mostrou que, apesar do crescimento da população e da renda brasileiras, o país não foi pressionado a aumentar significativamente suas importações de alimentos (como, por exemplo, a Índia), não foi obrigado a reduzir a expansão de suas exportações agrícolas pela pressão da demanda doméstica de terras para a produção de alimentos e, ainda, a agricultura brasileira aumentou a oferta de alimentos liberando mão de obra para suprir a demanda de trabalhadores no setor urbano da economia.

Neste contexto, Castro mostrou que a agricultura de outras regiões do mundo, tais como o Japão, e mesmo no caso clássico da França, não teve uma contribuição importante na demanda de produtos industriais. No caso brasileiro, no entanto, a contribuição do setor foi importante ao permitir que o mercado urbano, que surgia da substituição das importações e não do aumento da demanda das regiões agrícolas, se expandisse, sem que fosse estrangulado por problemas gerados na oferta de alimentos ou na incapacidade da agricultura de liberar mão de obra para as cidades ou capitais (caso do café, em São Paulo) para o investimento industrial ${ }^{9}$.

Na década seguinte, Castro participou de um debate com seus então colegas da Universidade Estadual de Campinas (Unicamp), entre eles Maria da Conceição Tavares, quanto à relevância das abordagens de Kalecki para entender a dinâmica do capitalismo e, no caso, o Brasil da época ${ }^{10}$. No livro O Capitalismo ainda é Aquele (1979), Castro discutiu 
sua visão de que o capitalismo estava sujeito, ainda, a ciclos e crises e esses movimentos não podiam ser explicados apenas por insuficiência de demanda, nem completamente superados por políticas econômicas ativas. Esse debate, como era comum à época, ficou acirrado, alcançando um público amplo com a publicação do artigo de Castro nos Cadernos de Opinião, no 15 (1980), intitulado "A Controvérsia da Demanda Efetiva", seguido de réplica e tréplica na Revista de Economia Política11.

Em A Economia Brasileira em Marcha Forçada (1985), Castro fez uma avaliação positiva do II Plano Nacional de Desenvolvimento (II PND) que se tornou clássica. Para muitos, inclusive para nós, esse trabalho, escrito com o colega da UFRJ e ex-aluno, Francisco Eduardo Pires, é seu melhor livro. Ele mostrou como foi possível avançar a industrialização brasileira em um momento em que a alternativa era a estagnação, como foi seguida por Argentina e Chile, que tiveram retumbantes fracassos na primeira metade da década. Castro tem uma interessante interpretação da trajetória interrompida do catch-up brasileiro que para ele é mais decorrente de erros na política macroeconômica ao final da década de 1970 e no início da década de 1980 do que no período anterior. Ou seja, a opção feita pelo Brasil, de ajustamento estrutural depois da primeira crise do petróleo, foi, segundo a interpretação de Castro, correta. Ela teria permitido ao Brasil concluir uma estrutura industrial, impedindo uma descontinuidade que abortaria o catch-up brasileiro, mudando as condições domésticas para enfrentar as condições externas. No entanto, para ele, depois do Segundo Choque do Petróleo e das novas condições internacionais, houve equívocos importantes nas políticas públicas, principalmente no caso da política macroeconômica, a partir do início da década de 1980.

Na década de 1990, Castro estudou a reestruturação da economia brasileira em vista do processo de liberalização tarifária. Embora não tenha sido contrário às privatizações, o foi quanto à forma como que essas foram feitas. No seu entender, perdeu-se uma oportunidade de criar empresas brasileiras líderes em vários setores da economia. Em sua passagem pelo governo Itamar Franco, como presidente do BNDES, não conseguiu implementar as políticas que gostaria e acabou por sair, quando Fernando Henrique Cardoso assumiu o Ministério da Fazen$\mathrm{da}^{12}$.

Neste período dos anos 1990, as análises de Castro passaram por uma transição, uma vez que se afastaram da abordagem estruturalista e, em 
contrapartida, passaram a estar crescentemente influenciadas pelas teorias neo-schumpeteriana e institucionalista. Esta transição não significou, todavia, uma renúncia absoluta ao estruturalismo ou, tampouco, a negação de suas obras anteriores. Na verdade, Castro entendeu que havia outros elementos importantes que o estruturalismo deixava de lado, sendo que, dependendo do contexto histórico e do fenômeno que se pretendia analisar, estes elementos poderiam ser fundamentais. Esta observação merece uma análise mais detalhada.

Para Castro, "o estruturalismo vê todo o tempo a ascendência das estruturas sobre a conduta [dos agentes]", contrariamente, por exemplo, ao neoclassicismo, que entende "que as escolhas são, ou devem ser, sempre individuais [...] é o agente singular sempre decidindo entre $\mathrm{Xe}$ Y, de acordo com suas preferências, os custos e recursos" (Castro, 2004:165-166). Neste contexto, segundo ele, a opção por utilizar a abordagem estruturalista depende da natureza do objeto que se pretende estudar.

No caso do Brasil, a discussão sobre as transformações ocorridas entre 1930 e 1980 bem se enquadravam dentro das linhas analíticas do estruturalismo. Em um contexto de atraso econômico em que não há Estado moderno ou indústria - como era o caso do Brasil na República Velha -, é de pouca utilidade focar nas escolhas individuais: "o agente econômico tradicional imerso em uma estrutura arcaica não vai tomar iniciativas do porte e natureza exigidos para que a economia seja efetivamente transformada" (ibidem:166). Assim, no contexto do rompimento com o atraso econômico, o importante seria fincar estacas, ou seja, mudar as estruturas para criar um novo conjunto de parâmetros a partir dos quais seriam definidas as condutas e escolhas dos agentes (ibidem).

Na turbulenta conjuntura da segunda metade dos anos 1980, contudo, Castro reavaliou a importância das expectativas e decisões individuais, bem como do papel-chave dos agentes (atores) nos processos de transformação econômica. Em A Solidão do Corredor de Longa Distância (2000:837), Castro deixa este ponto bastante claro:

Chocado com a agressividade e volatilidade dos comportamentos à medida que avançava a segunda metade dos anos 1980, comecei a indagar-me se as condutas individuais durante a fase heróica da industrialização - tão extremamente contrastantes com o que então presenciávamos - não se encontravam condicionadas por poderosos elementos motivadores/estabilizadores do comportamento. Foi a partir deste 
tipo de suspeita ou indagação que comecei a avançar em direção a uma nova visão. Encontrava-me a um passo de admitir a centralidade das instituições e das crenças compartilhadas (ou convenções) na coordenação das decisões econômicas.

Desta forma, desde essa época, as análises de Castro seriam enriquecidas por uma série de novos autores associados à nascente corrente neo-schumpeteriana e ao institucionalismo, os quais marcariam a sua visão sobre o passado e sobre o futuro da economia brasileira.

A partir dessas novas influências, Castro fez uma revisão da literatura sobre a experiência brasileira de industrialização entre 1930 e 1980. Nessa linha, reavaliou criticamente o conceito de ubstituição de impor tações. Para ele, a interpretação da substituição de importações seria pobre e mecanicista, uma vez que entendia "a industrialização retardatária como uma sucessão de respostas dadas (automaticamente?) aos estrangulamentos e alívios do balanço de pagamentos" (Castro, 2003:7). No caso, o problema estaria no fato de que o rompimento com o atraso econômico demandaria a construção de mecanismos de coordenação extramercado (idem, 2002:259). Mais precisamente, processos de industrialização retardatária envolveriam - conforme demonstrado pioneiramente por Gerschenkron (1962) - um amplo esforço de definição de atores especiais que assumirão as complexas tarefas envolvidas no esforço de emparelhamento com os países desenvolvidos (Castro, 1999:167 e 170). Desta forma, como a interpretação via substituição de importações omitia esta questão, Castro acreditava que a abordagem do catch-up era muito mais rica para abordar o tema, "já que a noção de catch-up, além de atribuir centralidade à decisão de transformar-se e às instituições para tanto construídas, confere a devida importância aos condicionantes tecnológicos" (idem, 2003:7).

Essa revisão histórica de Castro, embora instigante e importante para a compreensão de seu pensamento recente é, a nosso juízo, controversa. Substituição de importações foi um conceito usado para descrever a forma como a industrialização latino-americana ocorreu a partir dos choques externos, ou seja, como um "crescimento para dentro", em oposição ao "crescimento para fora" do período anterior à década de 1930. Portanto, ela não é uma explicação alternativa à abordagem de Gerschenkron, mas pode ser complementar a esse enfoque. Contudo, Castro tem razão quando diz que essa última perspectiva enfatiza o papel dos atores nos processos de industrialização retardatária. Castro, 
usando esse novo enfoque, reinterpretou a experiência brasileira de catch-up entre 1930 e 1980, em Renegade Development: Rise and Demise of State-led Development (1993) ${ }^{13}$. Neste artigo, ele investigou as razões que permitiram ao Brasil se industrializar e crescer aceleradamente sem contar com a mesma autonomia política e mecanismos de coordenação formal que outros latecomers bem-sucedidos. A conclusão a que ele chegou foi de que o Brasil compensou a insuficiência de coordenação formal mediante mecanismos informais de coordenação. Mais precisamente, o catching-up brasileiro teria sido, ao menos em parte, sustentado por duas convenções: a do crescimento e a da estabilidade ${ }^{14}$.

A do crescimento estaria associada ao clima de otimismo que se instaurou no Brasil a partir do governo de Juscelino Kubitschek (1956-1961), o qual teria criado a ideia de que o Brasil era um país vocacionado para o crescimento (ver Castro, 2000:837). Esta convicção de que o Brasil era um país que crescia e que continuaria crescendo teria tido um efeito de profecia autorrealizável, ou seja, a crença moldava as expectativas e ações dos agentes, gerando os resultados esperados, reforçando, com isso, a própria convenção. Neste contexto, o cerne do argumento é que, na existência deste mecanismo, a necessidade de intervenção estatal ficava reduzida (Castro, 1993:191).

Todavia, em um contexto de crescimento acelerado, era preciso também ter certo controle sobre a inflação, pois um processo inflacionário descontrolado criaria incertezas e poderia dissolver a confiança no futuro. Neste contexto, o sistema de indexação estabelecido a partir de 1964 resolveu este problema ao atuar como um substituto para a estabilidade, minimizando os efeitos deletérios da inflação. Assim, a combinação das duas convenções "definiu um ambiente que os agentes econômicos percebiam como altamente seguro e estimulante para investimentos de risco considerável", de modo que "a emergência desta cultura aliviava a missão dos policy-makers de dirigir a iniciativa privada para as direções almejadas pelo governo" (ver ibidem:194). Estas convenções estiveram operantes até os anos 1980, quando três violentos choques econômicos as dissolveram: 1) a crise da dívida externa do início daquela década; 2) o fracasso do Plano Cruzado; 3) a recessão provocada pelo Plano Collor em 1990 (ibidem:202-204).

As análises de Castro dos anos 1990 e 2000 foram influenciadas pelas grandes transformações ocorridas no país durante na década de 1990, as quais criaram uma nova realidade que condicionava inteiramente 
qualquer reflexão sobre os rumos da economia do país. No caso, a liberalização econômica e reestruturação produtiva dela resultante figuram entre as mais importantes transformações do período e receberam de Castro grande atenção.

Neste tocante, Castro (2001) e Castro e Proença (2001) argumentaram que houve ganhos de produtividade com a liberalização econômica, a partir de um esforço das empresas de reorganização produtiva e introdução de melhorias. Com isso, as empresas brasileiras ficaram aptas a colocar no mercado doméstico produtos atualizados a preços competitivos (ver Castro e Proença, 2001:182). No entanto, este tipo de estratégia concentrada em funções operacionais não era mais a fonte de vantagem competitiva nos centros desenvolvidos. Nestes centros, as funções fabris tinham perdido relevância e a geração de valor passara a estar ligada a funções como pesquisa e desenvolvimento (P\&D), gerência de marcas, design e marketing. Este fator explicaria as razões de as empresas brasileiras terem dificuldades em conquistar o mercado externo, mesmo após os esforços de modernização dos anos 1990 (ibidem:182-184).

Neste contexto, a interpretação de Castro sobre os resultados da liberalização econômica influenciou sua visão de política industrial. Aqui, novamente, o afastamento de Castro do estruturalismo e aproximação com a matriz neo-schumpeteriana se fará visível. Para ele, diante do quadro descrito acima, o desafio era motivar as empresas a partirem para as funções que aumentassem o valor agregado, ou seja, pesquisa e desenvolvimento (P\&D), gerência de marcas, design e marketing. Mais especificamente, o desafio para as empresas brasileiras terem sucesso no mercado internacional seria "desenvolver a capacidade para conceber, produzir e vender produtos com um perfil próprio de atributos e preços", ou seja, as empresas tinham que definir uma identidade e serem capazes de diferenciar os seus produtos (ibidem:189).

A ênfase neste diagnóstico levou Castro a concluir que, no contexto dos anos 1990 e 2000, o desafio não era mais modificar as estruturas. Na verdade, em vez de redefinir a estrutura produtiva, o foco deveria ser absorver conhecimentos e explorar o potencial das empresas no contexto das condições (estruturais) então existentes (Castro, 2004:167). Assim, começou a desenhar uma proposta de política industrial cujo foco estaria nas empresas e não, em setores ${ }^{15}$. No caso, em linhas gerais, o conceito consistia em uma política que ajudasse as empresas a avan- 
çarem quanto à produção de variedades, o que passava, por exemplo, pelo estímulo à criação do sistema nacional de inovação (idem, 2002:271). Esta linha de reflexão culminará em uma proposta concreta de política industrial baseada no potencial das empresas ${ }^{16}$.

A partir desta perspectiva, Castro começou, em meados dos anos 2000, a interessar-se pelo desenvolvimento econômico da China. Foi um dos primeiros economistas a apontar o crescente papel de protagonista do gigante asiático e entendia que, no presente e no futuro, o desempenho da indústria e as taxas de crescimento brasileiras estariam fortemente condicionados por este fator. Assim, o entendimento do catch-up chinês e as oportunidades e limitações que este processo impõe ao Brasil foram os temas prediletos de Castro nos últimos anos.

Em um texto intitulado Da Semiestagnação ao Crescimento no Mercado Sinocêntrico (2008), Castro chamou a atenção para o fato de que o dinamismo industrial chinês vinha reduzindo o preço internacional dos produtos manufaturados para os países industriais avançados, mas também para as economias diversificadas, de renda média ${ }^{17}$. Ao mesmo tempo, conforme discutido em Rumos da Economia - A Questão Aberta (2009), Castro mostrou que, por outro lado, a ascensão chinesa estava restaurando a escassez de matérias-primas e petróleo (Castro, 2009:26).

Desta forma, o mundo acima descrito é inverso ao discutido nos modelos de deterioração dos termos de troca Prebish-Singer - ou seja, há uma deterioração dos preços dos produtos industriais, com relação ao dos produtos primários. Esse cenário traria oportunidades, mas traz também riscos para os quais não estávamos preparados, sendo que a principal ameaça estaria no risco de o país passar por um processo de desindustrialização e/ou reprimarização da pauta de exportações. Neste contexto, as recém-descobertas reservas de petróleo na camada do pré-sal dão uma dimensão superlativa às oportunidades e riscos associados a esta nova realidade mundial que vem se configurando com a emergência do mundo sinocêntrico.

Diante deste quadro, Castro estava convicto de que alguma dose de regressão industrial inevitavelmente ocorrerá, como deixou claro em entrevista ao jornal Folha de S. Paulo, poucos meses antes de seu falecimento. Ele entendia que, independentemente da sobreapreciação da taxa de câmbio brasileira, há setores na indústria do país que simplesmente não têm condições de competir com os chineses, sendo que, no 
caso destes setores, políticas defensivas são contraproducentes. Todavia, esta constatação não significava uma capitulação. Castro enxergava uma série de oportunidades, por exemplo, "nos setores protegidos pela especificidade de nossos recursos naturais" por meio da "aplicação de conhecimentos existentes para desenvolver coisas próprias e originais" (ver Castro, 2011). Exemplos neste sentido seriam o desenvolvimento de plásticos verdes a partir da química do etanol ou ainda o desenvolvimento do setor naval a partir da exploração das águas profundas (ibidem; 2009:35). O Brasil teria a possibilidade não apenas de preservar uma boa parcela de sua estrutura industrial, mas também de fazer grandes avanços em novas frentes. O aproveitamento destas oportunidades passava então pelo desenho inteligente de políticas públicas, tema a que Castro estava se dedicando.

Todas as discussões levantadas por Castro, das mais simples às mais complexas, traziam sempre sua visão (certamente influenciadas pela sua leitura de Gerschenkron) de que, afinal, o Brasil seria capaz de superar as barreiras ao seu crescimento sustentado. Ou seja, embora apontasse que o Brasil era um caso de catch-up interrompido, ele acreditava que seria possível reposicionar a indústria e reencontrar o caminho do desenvolvimento. Nesse sentido, para sua obra se aplica o nome que Albert Hirschman, um outro autor que ele apreciava, deu para seu livro de ensaios sobre desenvolvimento e a América Latina: Um Viés de Esperança (A Bias for Hope) (ver Hirschman, 1985). Castro acreditava na capacidade de a sociedade brasileira forjar seu futuro. Como escreveu Furtado na Pré-Revolução Brasileira, a ideia de que o destino do país poderia ser construído domesticamente gerava um sentimento de inquietação. Mas, para Castro, era uma inquietação otimista. Sua perda é lamentável porque seu pensamento estava em plena evolução. Morreu como viveu: um homem ativo e generoso. Resta a nós lamentar a perda do intelectual e do amigo.

(Recebido para publicação em outubro de 2011) 


\section{NOTAS}

1. Essa acabou por ser uma agenda frustrada. O debate entre estruturalistas, como Furtado, que defendiam uma agenda de reformas, e liberais, como Gudin e Bulhões, que criticavam o que consideravam os três desequilíbrios básicos da economia brasileira: os populismos fiscal, do crédito e o salarial, terminou com o Golpe Militar de 1964. Ver Prado e Earp (2003:210-213).

2. A entrevista está publicada em livro organizado por Guido Mantega, José Márcio Rego e Paul Singer (1999). Para a tradução do livro A Pré-Revolução Brasileira mencionada, ver Furtado (1964).

3. Para uma discussão sobre a origem da expressão Intelectual Público, ver Brick (2011).

4. Tal como Sartre, Wright Mills também enfatizava a importância da responsabilidade do intelectual para a consciência moral do seu tempo. Sobre Sartre como Intelectual Público, ver Swartz e Zolberg (2007). Sobre Mills, ver Brick (2011).

5. O dicionário Webster's define Scholar como "pessoa erudita, treinada em um campo especial de conhecimento, como literatura, arte etc." (nossa tradução). Ver New Webster's (1968).

6. O artigo "Além da Estagnação" foi publicado em Tavares (1972).

7. Ver Castro (1969:81-146 - "Ensaio 2, Agricultura e Desenvolvimento no Brasil”).

8. Observe-se que vários pontos dessa abordagem foram previamente discutidos em textos de H. A. Innis publicados na década de 1930, mas foi Waltkins que pela primeira fez organizou essa discussão e propôs uma teoria de desenvolvimento baseada na exportação de produtos básicos (staples). Para uma discussão sobre essa teoria, ver Altman (2003).

9. A interpretação de Castro corroborava a visão de Delfim Netto (1966) que também não via na agricultura um impedimento para o desenvolvimento industrial. A tese de que não era necessário reformar a estrutura agrária brasileira por razões econômicas (embora fosse desejável por razões sociais) foi, ao final, corroborada com o papel da agricultura brasileira no período que ficou conhecido como "Milagre Econômi$\mathrm{co}^{\prime \prime}$.

10. Maria da Conceição Tavares apresentou uma interpretação da macroeconomia baseada na abordagem de Kalecki e uma aplicação desse enfoque para a economia brasileira na sua tese de livre-docência, defendida em 1974, mais tarde publicada pela editora da Unicamp. Ver Tavares (1998).

11. A réplica foi feita por Beluzzo e Tavares (1981) e respondida por Castro (1981).

12. Castro voltou a participar diretamente de um governo em 2004, quando assumiu a Diretoria de Planejamento do BNDES, cargo que exerceu até 2007.

13. Castro considerava este artigo verdadeiramente um esboço. Ele pretendia algum dia retomar o tema para fazer uma análise mais densa e equilibrada sobre a questão.

14. O tema sobre a relação entre convenções e desenvolvimento no Brasil veria a ser, posteriormente, discutido em profundidade, através de outra perspectiva, por seu colega do Instituto de Economia (IE-UFRJ) e amigo desde a juventude, Fábio Erber, em uma série de trabalhos nos anos 2000. Ver Erber (2008, 2009, 2010a, 2010b, 2011). Para uma discussão sobre o enfoque de Erber sobre Convenções, ver Prado (2011). 
15. “É, pois, necessário, liberar-se da tradição vinda do paradigma setorial - que abafa ou anula a sensibilidade para o idiossincrático. Afinal, em vez de replicar (e, portanto, convergir) há agora que cultivar as diferenças. E, para tanto, o importante são as possibilidades percebidas pelos que decidem. Setor, em contraposição, não decide" (Castro, 2002:263-264).

16. Para detalhes, ver Castro e Ávila (2004).

17. Sob muitos aspectos, a discussão levantada pelo autor lembra as implicações das mudanças dos preços relativos com o aprofundamento da industrialização europeia a partir da Segunda Revolução Industrial. 


\section{REFERÊNCIAS BIBLIOGRÁFICAS}

ALTMAN, Morris. (2003), "Staple Theory and Export Led-Growth: Constructing Differential Growth". Australian Economic History Review, vol. 43, no 3, pp. 230-255.

BELUZZO, Luiz Gonzaga; TAVARES, Maria da Conceição. (1981), "Ainda a Controvérsia da Demada Efetiva: Uma Pequena Contribuição". Revista de Economia Política, vol. 3, no 1 .

BRICKS, Howard. (2011), “C. Wright Mills, Sociology, and the Politics of the Public Intellectual". Modern Intellectual History, vol. 8, no 2, pp. 391-409.

CASTRO, Antônio Barros de. (2011), “O Brasil Tem de se Reinventar para Tratar com a China". Entrevista concedida à jornalista Cláudia Antunes, Folha de S. Paulo, 11 de abril.

. (2009), "Rumos da Economia - A Questão Aberta”, in CPDoc (org.), 200 Anos do Ministério da Fazenda - Economistas. Rio de Janeiro, Editora FGV.

(2008), "From Semi-stagnation to Growth in a Sino-Centric Market". Revista de Economia Política, vol. 28, pp. 15-45.

. (2004), “Entrevista com Antônio Barros de Castro". Pesquisa \& Debate, vol. 15, pp. 163-176.

_ (2003), O Segundo Catch-Up Brasileiro: Características e Limitações. Mimeo.

. (2002), "A Rica Fauna da Política Industrial e a sua Nova Fronteira". Revista Brasileira de Inovação, vol. 1, no 2, pp. 253-274.

. (2001), “A Reestruturação da Indústria Brasileira nos Anos 90: Uma Interpretação". Revista de Economia Política, vol. 21, no 3, pp. 3-26.

. (2000), “A Solidão do Corredor de Longa Distância". Economia Aplicada, vol. 4, no 4, pp. 823-839.

. (1999), "Antonio Barros de Castro", in G. Mantega, J. M. Rego e P. Singer (orgs.), Conversas com Economistas Brasileiros II. São Paulo, Editora 34.

. (1993), “Renegade Development: Rise and Demise of State-Led Development in Brazil", in W. Smith, C. H. Acuña e E. A. Gamarra (orgs.), Democracy, Markets and Structural Reform in Latin America. Miami, Transaction Publishers.

(1981), "A Controvérsia da Demanda Efetiva: O Deslocamento da Questão". Revista de Economia Política, vol.1, no 4 .

. (1980), “A Controvérsia da Demanda Efetiva". Cadernos de Opinião, no 15.

. (1979), O Capitalismo ainda é Aquele. Rio de Janeiro, Editora Forense.

(1972) [1969], Sete Ensaios sobre a Economia Brasileira. 2a ed. Rio de Janeiro, Editora Forense.

e ÁVILA, Jorge. (2004), Uma Política Industrial e Tecnológica Voltada para o Potencial das Empresas. Mimeo.

CASTRO, Antônio Barros de e LESSA, Carlos. (1967), Introdução à Economia. Uma Abordagem Estruturalista. 36a ed. Rio de Janeiro, Forense Universitária. 
CASTRO, Antônio Barros de e PROENÇA, Adriano. (2001), Novas Estratégias Industriais: Sobrevida ou Inflexão?", in J. P. dos Reis Velloso (org.), Como Vão o Desenvolvimento e a Democracia no Brasil? Rio de Janeiro, José Olympio Editora.

CASTRO, Antônio Barros de e SOUZA, Francisco Eduardo Pires de. (1985), A Economia Brasileira em Marcha Forçada. Rio de Janeiro, Paz e Terra.

DELFIM NETTO, Antônio. (1966), “Agricultura e Desenvolvimento no Brasil”. Estudos Anpes, no 5 .

ERBER, Fábio S. (2011), “As Convenções de Desenvolvimento no Governo Lula". Revista de Economia Política, vol. 31, no 1.

. (2010a), “Convenções de Desenvolvimento no Brasil Contemporâneo: Um Ensaio de Economia Política". Textos para Discussão, Cepal-Ipea.

. (2010b), “Inovação Tecnológica na Indústria Brasileira no Passado Recente: Uma Resenha da Literatura Econômica". Textos para Discussão, Cepal-Ipea.

. (2009), "Convenções de Desenvolvimento no Brasil Contemporâneo". Insight Inteligência, Ano XI, no 44 .

. (2008), The Evolution of Development Conventions. XXII International Schumpeter Society Conference.

FURTADO, Celso. (2009), A Pré-Revolução Brasileira. Reedição de original de 1962. Recife, Editora Universitária (UFPE).

. (1972), A Análise do "Modelo Brasileiro". Rio de Janeiro, Paz e Terra.

. (1964), Le Brésil à l’Heure du Choix. (Prefácio de P. Massé, tradução de Jean Chouard). Paris, Plon.

GERSCHENKRON, Alexander. (1962), Economic Backwardness in Historical Perspective. Harvard, Harvard University Press.

HIRSCHMAN, Albert. (1985), Bias for Hope: Essays on Development and Latin America. Boulder, Westview Press.

MANTEGA, Guido; REGO, José Márcio; SINGER, Paul. (1999), Conversas com Economistas Brasileiros II. São Paulo, Editora 34.

PRADO, Luiz Carlos D. (2011), “Fábio Erber, o Economista e suas Circunstâncias”. Revista de Economia Contemporânea, vol.15, no 1 .

; EARP, Fábio S. (2003), “O Milagre Brasileiro: Crescimento Acelerado, Integração Internacional e Concentração de Renda -1967-1973", in J. Ferreira e L. Delgado (orgs.), O Brasil Republicano: O Tempo da Ditadura. Rio de Janeiro, Civilização Brasileira.

PREBISCH, Raúl. (2011), “A Política Comercial nos Países Insuficientemente Desenvolvidos, do Ponto de Vista Latino-Americano", in R. Prebisch, O Manifesto Latino-Americano e Outros Ensaios. (Organização e Introdução de Adolfo Gurrieri). Rio de Janeiro, Contraponto/Centro Internacional Celso Furtado de Políticas para o Desenvolvimento.

SWARTZ, David L. e ZOLBERG, Vera L. (2007), "Sartre for the Twenty-first Century?". Theory and Society, vol. 36, pp. 215-222. 
TAVARES, Maria da Conceição. (1998), Acumulação de Capital e Industrialização no Brasil. Campinas, Ed. da Unicamp. . (1972), Da Substituição de Importações ao Capitalismo Financeiro. Rio de Janeiro, Zahar.

WEBSTER'S New World Dictionary. College Edition. New York e Cleveland, 1968.

WALTKINS, Melville. (1963), "The Staple Theory of Economic Growth". The Canadian Journal of Economics and Political Science/Revue Canadienne d'Economique et de Science Politique, vol. 29, no 2, pp. 141-158.

\begin{abstract}
Economist in the Labyrinth: an Obituary for Antônio Barros de Castro

Antonio Barros de Castro participated actively for 40 years in the academic life and public debate on development policies. This insightful intellectual belonged to a generation of professors that influenced both the academic debate and Brazilian society's interpretations of its problems and alternatives. Castro stood out for his meticulous analysis of the problems he studied and for his critical acumen, having spearheaded various debates on the country's economic problems and the strategy to overcome them. According to his interpretation, Brazil was a case of interrupted economic "catch-up", and a major portion of his research work focused on the discussion of alternatives for the country to resume its path to sustained growth. The current article aims to discuss some of the principal themes and studies developed by Castro during his long and successful academic career, as an overview of the economist's contributions.
\end{abstract}

Key words: economic development; Brazilian economic thought; Brazil's economic history 